\title{
Advanced Coronary Artery Calcification and Cerebral Small Vessel Diseases in the Healthy Elderly
}

\author{
Beom Joon Kim, MD; Seung-Hoon Lee, MD, PhD; Chi Kyung Kim, MD; Wi-Sun Ryu, MD; \\ Hyung-Min Kwon, MD, PhD; Su-Yeon Choi, MD, PhD; Byung-Woo Yoon, MD, PhD
}

\begin{abstract}
Background: Coronary artery calcification (CAC) scores are widely accepted to predict risk of coronary heart diseases and are associated with atherosclerosis in other vasculatures. Cerebral small vessel diseases (SVDs), including white matter lesions (WML), silent lacunar infarction (SLI) and cerebral microbleeds (CMB), are considered to develop in conjunction with pro-atherogenic conditions, measured by CAC scores.
\end{abstract}

\begin{abstract}
Methods and Results: Of 672 individuals aged $\geq 65$ years that underwent health screening, 312 subjects with brain magnetic resonance imagings (MRIs) were enrolled in this study. The distribution of baseline characteristics among individuals with or without MRIs was not different. Clinical and laboratory information was collected and CAC scores were measured using multi-detector computed tomography. Cerebral SVD were independently assessed by 2 raters who were unaware of the CAC scores. The prevalence of CAC (CAC>0) was $71.7 \%$ in men and $50.0 \%$ in women. The associations between moderate-to-extensive CAC (CAC score $\geq 100$ ) and WML (adjusted odds ratio and 95\% confidence interval, 4.99 and 1.33-18.73), SLI (5.04 and 1.86-13.63) and CMB (6.07 and 1.54-23.94) remained significant after adjusting for relevant confounders.
\end{abstract}

Conclusions: This study documents significant associations between CAC and cerebral SVDs. The findings suggest that SVDs in the brain and CAC in the heart may develop under similar systemic pathogenic processes. (Circ J 2011; 75: 451-456)

Key Words: Cerebral microbleeds; Cerebral small vessel disease; Coronary artery calcification; Silent lacunar infarction; White matter lesion

$\mathbf{C}$ oronary artery calcification (CAC) scores have recently gained a reputation for estimating the future risk of coronary heart disease and have been recommended for the assessment of individuals with intermediate cardiovascular risks. ${ }^{1}$ CAC measurements are able to quantify subclinical coronary artery atherosclerosis and predict the future risk of coronary heart disease ${ }^{2,3}$ and cerebrovascular disease,,, 5 and the progression of atherosclerotic coronary artery disease. ${ }^{6,7}$ The predictive power of CAC scores was successfully evaluated in a multi-ethnic group, ${ }^{8}$ and is more accurate than conventional cardiovascular risk factors. ${ }^{9}$ Recent advances have also revealed an association between CAC scores and atherosclerotic diseases in other vasculatures, which implies that CAC scores could be used to estimate systemic subclinical atherosclerotic burden. ${ }^{10-14}$

\section{Editorial p 272}

In the brain, various subclinical lesions involving small arteries to arterioles develop before clinical manifestation of diseases. Cerebral small vessel diseases (SVDs), which include white matter lesions (WML), silent lacunar infarction (SLI) and cerebral microbleeds (CMB), are detected in 4-6\% of the general population. Cerebral SVDs develop in close relation to traditional cardiovascular risk factors and increases the future risk of stroke and cognitive impairment. ${ }^{15}$

In this context, we speculated that a close relation exists between CAC and cerebral SVDs, and that both subclinical phenomena may share similar systemic pathological processes, such as pro-atherogenic internal milieu. Accordingly, we investigated the association between CAC scores and

Received August 2, 2010; revised manuscript received September 10, 2010; accepted October 5, 2010; released online December 10, 2010 Time for primary review: 9 days

Department of Neurology, Seoul National University Hospital, Seoul (B.J.K., S.-H.L., C.K.K., W.-S.R., B.-W.Y.); Department of Neurology, SMG-SNU Boramae Medical Center, Seoul (H.-M.K.); and Department of Internal Medicine, Seoul National University Hospital Healthcare System Gangnam Center, Seoul (S.-Y.C.), Republic of Korea

Two authors contributed equally (S.-H.L., B.-W.Y.).

Mailing address: Seung-Hoon Lee, MD, PhD, Department of Neurology, Seoul National University Hospital, 28 Yeongun-dong, Jongrogu, Seoul 110-744, Republic of Korea. E-mail: sb0516@snu.ac.kr or Byung-Woo Yoon, MD, PhD, Department of Neurology, Seoul National University Hospital, 28 Yeongun-dong, Jongro-gu, Seoul 110-744, Republic of Korea. E-mail: bwyoon@ snu.ac.kr

ISSN-1346-9843 doi:10.1253/circj.CJ-10-0762

All rights are reserved to the Japanese Circulation Society. For permissions, please e-mail: cj@j-circ.or.jp 


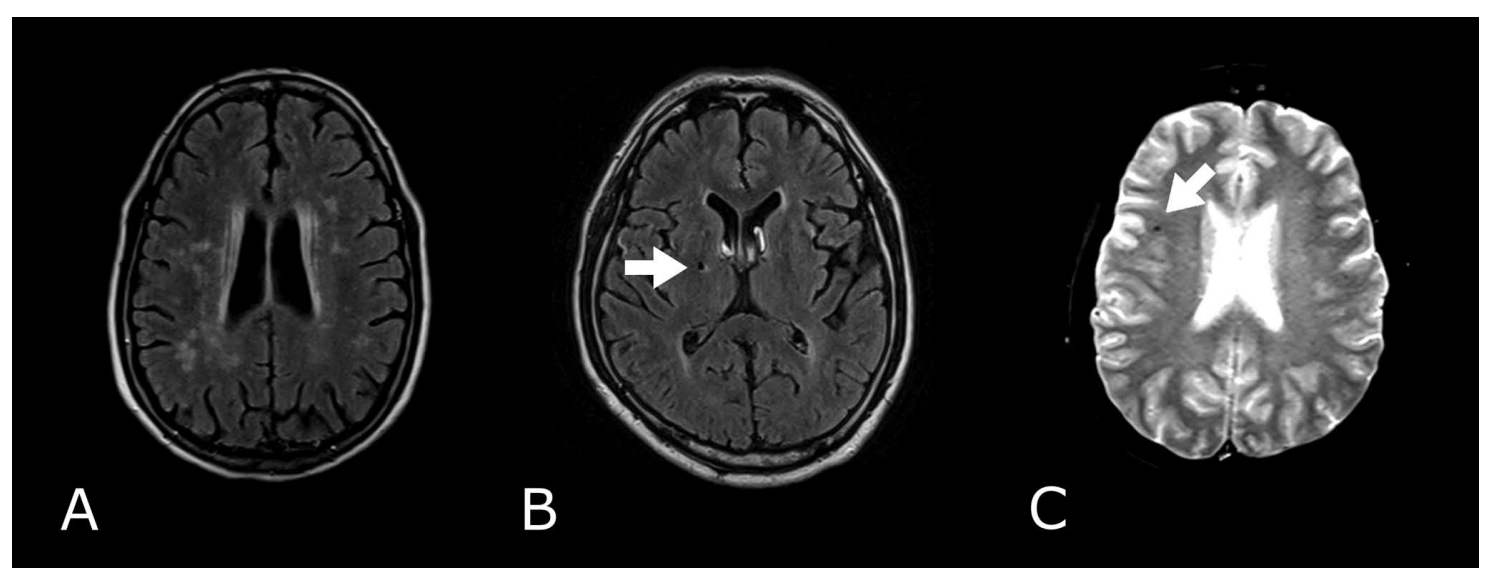

Figure. A representative figure of cerebral small vessel diseases: white matter lesions (A), silent lacunar infarction (B) and cerebral microbeed $(\mathbf{C})$.

\begin{tabular}{|c|c|c|}
\hline & $\begin{array}{c}\text { All } \\
\text { participants } \\
(n=672)\end{array}$ & $\begin{array}{c}\text { Participants } \\
\text { with brain } \\
\text { MRI }(n=312)\end{array}$ \\
\hline \multicolumn{3}{|l|}{ Demographic variable } \\
\hline Male gender & $443(65.9 \%)$ & 198 (63.5\%) \\
\hline Age (years) & $69.0 \pm 4.0$ & $68.7 \pm 3.7$ \\
\hline \multicolumn{3}{|l|}{ Clinical variables } \\
\hline Hypertension & $389(57.9 \%)$ & $183(58.7 \%)$ \\
\hline Diabetes & $188(28.0 \%)$ & $81(26.0 \%)$ \\
\hline Hypercholesterolemia & $109(16.2 \%)$ & $48(15.4 \%)$ \\
\hline Exposure to smoking* & $215(37.0 \%)$ & $117(37.5 \%)$ \\
\hline \multicolumn{3}{|l|}{ Anthropometric variables } \\
\hline $\mathrm{SBP}(\mathrm{mmHg})$ & $128.4 \pm 17.7$ & $129.0 \pm 17.8$ \\
\hline $\mathrm{DBP}(\mathrm{mmHg})$ & $77.7 \pm 10.9$ & $78.1 \pm 10.5$ \\
\hline Body mass index $\left(\mathrm{kg} / \mathrm{m}^{2}\right)$ & $24.2 \pm 3.3$ & $24.4 \pm 2.9$ \\
\hline Waist circumference (cm) & $89.7 \pm 8.1$ & $90.2 \pm 2.9$ \\
\hline \multicolumn{3}{|l|}{ Laboratory variables } \\
\hline Glucose (mmol/L) & $5.9 \pm 1.5$ & $5.9 \pm 1.4$ \\
\hline Total cholesterol (mmol/L) & $5.1 \pm 0.9$ & $5.1 \pm 0.9$ \\
\hline Triglyceride $(\mathrm{mmol} / \mathrm{L})$ & $1.3 \pm 0.7$ & $1.4 \pm 0.8$ \\
\hline HDL cholesterol (mmol/L) & $1.4 \pm 0.4$ & $1.4 \pm 0.4$ \\
\hline LDL cholesterol (mmol/L) & $3.4 \pm 0.9$ & $3.4 \pm 0.8$ \\
\hline $\mathrm{CRP}(\mathrm{mg} / \mathrm{L})$ & $1.8 \pm 4.0$ & $1.7 \pm 3.5$ \\
\hline \multicolumn{3}{|l|}{$\begin{array}{l}\text { Coronary artery calcification } \\
\text { score (M/F) }\end{array}$} \\
\hline $25^{\text {th }}$ percentile & $0 / 0$ & $0 / 0$ \\
\hline $50^{\text {th }}$ percentile & $45 / 3$ & $36 / 1$ \\
\hline $75^{\text {th }}$ percentile & $246 / 74$ & $229 / 56$ \\
\hline $90^{\text {th }}$ percentile & $719 / 230$ & $669 / 230$ \\
\hline
\end{tabular}

Values are presented as means \pm standard deviations or numbers (\%).

$\mathrm{MRI}$, magnetic resonance imaging; SBP, systolic blood pressure; DBP, diastolic blood pressure; HDL, high-density lipoprotein; LDL, low-density lipoprotein; CRP, C-reactive protein.

*Information regarding exposure to smoking was missing in 91 $(13.5 \%)$ of the 672 "All-participants" $(17.9 \%)$ and in $16(5.1 \%)$ of the 312 subjects with a brain MRI. cerebral SVDs in healthy, elderly individuals that were free of neurologic and cardiac diseases.

\section{Methods}

\section{Study Population}

Seoul National University Hospital Healthcare System Gangnam Center provides detailed health screening services for individuals with no overt diseases in need of instant medical attention and who requests this service at their own expense. Between October 2003 and December 2008, 5,420 individuals underwent health screening including CAC scoring. Health screening participants consisted of 3,542 (65.4\%) male and 1,878 (34.6\%) female subjects, and their mean age was $53.6 \pm 9.5$ years. From a total of 672 participants $\geq 65$ years old without alleged cardiac or neurological disease, 312 subjects $(46.4 \%)$, who requested brain magnetic resonance imaging (MRI) as a health screening, were enrolled in this study. Participants $<65$ years of age were excluded due to the rarity of cerebral SVDs in this population. This study was approved by the institutional review board at Seoul National University Hospital and all included subjects provided informed consent.

\section{Measurement of CAC}

Computed tomographic scanning of the coronary artery was performed using a 16-slice multidetector system (SOMATOM Sensation 16, Siemens Healthcare, Erlangen, Germany). Images were acquired in 3.0-mm slices throughout coronary artery regions using a prospectively ECG-triggered scan acquisition at a $50 \%$ of the RR interval and slice collimation of $4 \times 2.5 \mathrm{~mm}$ at $120 \mathrm{kV}$ and $120 \mathrm{mAs} .{ }^{16}$ All images were transferred to a stand-alone workstation and CAC scores were calculated using an automated computer program (Wizard VB10B, SynGo, Siemens Healthcare). CAC scores were produced using the Agatston method. ${ }^{17}$ Briefly, the area of $\mathrm{CAC}$ is defined as at least $1 \mathrm{~mm}^{2}$ with a computed tomography density $\geq 130$ Hounsfield Units (HU). A score for each region was calculated by multiplying the area size and the density score, which derived from the peak intensity of this focus ((1) 130-199HU; (2) 200-299HU; (3) 300-399HU; (4) $\geq 400 \mathrm{HU})$. The total CAC score was computed by adding 


\begin{tabular}{|c|c|c|c|c|}
\hline & $\begin{array}{c}\text { No CAC } \\
\text { (CACS, } 0 ; n=113)\end{array}$ & $\begin{array}{c}\text { Mild CAC } \\
\text { (CACS, 1-99; } n=104)\end{array}$ & $\begin{array}{c}\text { Moderate-to- } \\
\text { extensive CAC } \\
\text { (CACS, } \geq 100 ; n=95)\end{array}$ & $P$ for trend \\
\hline \multicolumn{5}{|l|}{ Demographic variable } \\
\hline Male gender & $56(49.6 \%)$ & $67(64.4 \%)$ & 75 (78.9\%) & $<0.01$ \\
\hline Age & $67.9 \pm 3.2$ & $69.0 \pm 3.7$ & $69.3 \pm 4.1$ & $<0.01$ \\
\hline \multicolumn{5}{|l|}{ Clinical variables } \\
\hline Hypertension & $54(47.8 \%)$ & $68(65.4 \%)$ & $61(64.2 \%)$ & 0.01 \\
\hline Diabetes & $20(17.7 \%)$ & $22(21.2 \%)$ & $39(41.1 \%)$ & $<0.01$ \\
\hline Hypercholesterolemia & $19(16.8 \%)$ & $20(19.2 \%)$ & $9(9.5 \%)$ & 0.16 \\
\hline Exposure to smoking* & $29(27.6 \%)$ & $36(36.0 \%)$ & $52(57.1 \%)$ & $<0.01$ \\
\hline \multicolumn{5}{|l|}{ Anthropometric variables } \\
\hline $\mathrm{SBP}(\mathrm{mmHg})$ & $125.6 \pm 17.0$ & $130.5 \pm 17.2$ & $131.4 \pm 19.0$ & 0.02 \\
\hline $\mathrm{DBP}(\mathrm{mmHg})$ & $77.6 \pm 10.3$ & $77.7 \pm 10.4$ & $79.3 \pm 10.8$ & 0.25 \\
\hline Body mass index $\left(\mathrm{kg} / \mathrm{m}^{2}\right)$ & $24.6 \pm 3.0$ & $24.0 \pm 2.9$ & $24.5 \pm 2.8$ & 0.75 \\
\hline Waist circumference $(\mathrm{cm})$ & $91.0 \pm 7.9$ & $89.8 \pm 8.7$ & $89.8 \pm 8.2$ & 0.30 \\
\hline \multicolumn{5}{|l|}{ Laboratory variables } \\
\hline Glucose (mmol/L) & $5.6 \pm 1.0$ & $5.7 \pm 1.1$ & $6.3 \pm 1.9$ & $<0.01$ \\
\hline Total cholesterol (mmol/L) & $5.2 \pm 0.8$ & $5.1 \pm 0.9$ & $4.9 \pm 0.9$ & 0.07 \\
\hline Triglyceride (mmol/L) & $1.2 \pm 0.6$ & $1.5 \pm 1.2$ & $1.4 \pm 0.6$ & 0.21 \\
\hline HDL cholesterol (mmol/L) & $1.4 \pm 0.4$ & $1.3 \pm 0.4$ & $1.3 \pm 0.3$ & 0.15 \\
\hline LDL cholesterol (mmol/L) & $3.5 \pm 0.8$ & $3.5 \pm 0.9$ & $3.3 \pm 0.9$ & 0.11 \\
\hline CRP (mg/L) & $1.9 \pm 4.7$ & $1.7 \pm 2.9$ & $1.3 \pm 2.0$ & 0.20 \\
\hline \multicolumn{5}{|l|}{ Cerebral small vessel disease } \\
\hline Advanced white matter lesion & $4(3.5 \%)$ & $8(7.7 \%)$ & $14(14.7 \%)$ & $<0.01$ \\
\hline Silent lacunar infarction & $10(8.8 \%)$ & $18(17.3 \%)$ & $24(25.3 \%)$ & $<0.01$ \\
\hline Cerebral microbleed & $5(4.4 \%)$ & $9(8.7 \%)$ & $14(14.7 \%)$ & 0.01 \\
\hline
\end{tabular}

Values are presented as means \pm standard deviations or as numbers $(\%)$.

CAC, coronary artery calcification; CACS, coronary artery calcification score. Other abbreviations see in Table 1.

$P$ values for trend were calculated by analyses of variance test or chi-square tests trend, as appropriate.

*Information regarding the exposure to smoking was missing in 16 subjects.

up each of the scores for all calcified lesions in the epicardial coronary system.

\section{Measurement of Cerebral SVD and Cardiovascular Risk Factors}

MRI studies were performed using a 1.5-Tesla superconducting magnet (CHORUS, ISOL Technology, Seoul, Republic of Korea). The standardized MRI protocol included axial T2weighted spin echo, T1-weighted spin echo, fluid-attenuated inversion recovery (FLAIR) and axial $\mathrm{T} 2 *$-weighted gradient-echo (GRE) sequences. WML were classified as absent or present as punctuate, early confluent, or confluent lesions based on FLAIR image evaluations, ${ }^{18}$ and the early confluent or confluent lesions were defined as advanced WML. SLI were defined as focal lesions measuring $3-15 \mathrm{~mm}$ in diameter with signal intensities corresponding to liquor, and surrounded by a hyperintense gliotic rim on FLAIR images. ${ }^{19} \mathrm{CMBs}$ were defined as homogeneous, round signal loss lesions of diameter up to $5 \mathrm{~mm}$ on GRE images (Figure). ${ }^{20}$ Cerebral SVD were rated by 2 independent reviewers (W.-S.R. and C.K.K.) who were unaware of clinical information or CAC scores with good inter-rater agreement $(\kappa$-values of agreement were 0.70 , 0.66 and 0.86 , respectively). Disagreements were settled by discussion with a third rater (B.J.K.).

Baseline information on demographic and cardiovascular risk factors was collected during health examinations on the following: gender, age, hypertension (previous use of antihypertensive medication, or systolic blood pressure (BP) $\geq 140 \mathrm{mmHg}$ or diastolic $\mathrm{BP} \geq 90 \mathrm{mmHg}$ ), diabetes (previous use of antidiabetic medication or fasting blood glucose $>7.0 \mathrm{mmol} / \mathrm{L}$ ), hyperlipidemia (previous use of lipid-lowering medication, total cholesterol (TC) $>6.0 \mathrm{mmol} / \mathrm{L}$ or lowdensity lipoprotein cholesterol $>4.14 \mathrm{mmol} / \mathrm{L}$ ) and exposure to smoking (current smoker or having a regular smoking habit in the past). We also measured anthropometric variables, which included systolic and diastolic BP, waist circumference and body mass index. Laboratory assessments included glucose, TC, high-density lipoprotein cholesterol, triglyceride and C-reactive protein (CRP) levels. Low-density lipoprotein cholesterol levels were calculated using the Friedewald equation. ${ }^{21}$

\section{Data Analysis}

We first compared the characteristics of the $672 \geq 65$ yearold health screened participants and the 312 subjects with brain MRI studies to ensure comparability between subjects with and without brain MRI. CAC scores were categorized as no CAC (CAC score of 0), mild CAC (CAC score of 199) and moderate-to-extensive CAC (CAC score of $\geq 100){ }^{22}$ The distribution of clinical and laboratory variables in relation to increased CAC severity was also examined. Trends across categorized CAC severity were performed using the Mantel-Haenszel chi-square test and by analysis of variance. Univariate analysis was performed using the t-test or the chi-square test, as appropriate, to investigate associations between cerebral SVD and baseline characteristics. Associa- 


\begin{tabular}{|c|c|c|c|c|c|c|c|c|c|}
\hline & \multicolumn{3}{|c|}{ Advanced white matter lesion } & \multicolumn{3}{|c|}{ Silent lacunar infarction } & \multicolumn{3}{|c|}{ Cerebral microbleeds } \\
\hline & $\begin{array}{c}\text { Present } \\
(\mathrm{n}=26)\end{array}$ & $\begin{array}{l}\text { Absent } \\
(n=286)\end{array}$ & $P$ value & $\begin{array}{c}\text { Present } \\
(n=52)\end{array}$ & $\begin{array}{l}\text { Absent } \\
(n=260)\end{array}$ & $P$ value & $\begin{array}{c}\text { Present } \\
(n=28)\end{array}$ & $\begin{array}{l}\text { Absent } \\
(n=284)\end{array}$ & $P$ value \\
\hline \multicolumn{10}{|l|}{ Demographic variable } \\
\hline Male gender & $12(46.2 \%)$ & $186(65.0 \%)$ & 0.06 & 31 (59.6\%) & 167 (64.2\%) & 0.53 & 17 (60.7\%) & $181(63.7 \%)$ & 0.75 \\
\hline Age & $70.9 \pm 4.8$ & $68.5 \pm 3.5$ & $<0.01$ & $69.4 \pm 4.3$ & $68.6 \pm 3.6$ & 0.15 & $68.6 \pm 3.6$ & $69.5 \pm 4.4$ & 0.23 \\
\hline \multicolumn{10}{|l|}{ Clinical variables } \\
\hline Hypertension & $21(80.8 \%)$ & $162(56.6 \%)$ & 0.02 & $35(67.3 \%)$ & $148(56.9 \%)$ & 0.16 & $20(71.4 \%)$ & $163(57.4 \%)$ & 0.15 \\
\hline Diabetes & $8(30.8 \%)$ & $73(25.5 \%)$ & 0.56 & $16(30.8 \%)$ & $65(25.0 \%)$ & 0.39 & $8(28.6 \%)$ & $73(25.7 \%)$ & 0.74 \\
\hline Hypercholesterolemia & $5(19.2 \%)$ & $43(15.0 \%)$ & 0.57 & $12(23.1 \%)$ & $36(13.8 \%)$ & 0.09 & $4(14.3 \%)$ & $44(15.5 \%)$ & $1.00 \ddagger$ \\
\hline Exposure to smoking* & $8(32.0 \%)$ & $109(40.2 \%)$ & 0.42 & $19(39.6 \%)$ & $98(39.5 \%)$ & 0.99 & $11(42.3 \%)$ & $106(39.3 \%)$ & 0.76 \\
\hline \multicolumn{10}{|l|}{ Anthropometric variables } \\
\hline SBP $(\mathrm{mmHg})$ & $136.3 \pm 21.5$ & $128.3 \pm 17.3$ & 0.03 & $135.2 \pm 21.4$ & $127.8 \pm 16.8$ & $<0.01$ & $134.2 \pm 15.1$ & $128.5 \pm 18.0$ & 0.11 \\
\hline $\mathrm{DBP}(\mathrm{mmHg})$ & $79.3 \pm 11.1$ & $78.0 \pm 10.4$ & 0.56 & $78.7 \pm 11.7$ & $78.0 \pm 10.2$ & 0.67 & $80.7 \pm 10.5$ & $77.9 \pm 10.4$ & 0.18 \\
\hline Body mass index $\left(\mathrm{kg} / \mathrm{m}^{2}\right)$ & $24.3 \pm 2.4$ & $24.4 \pm 3.0$ & 0.80 & $24.0 \pm 2.6$ & $24.5 \pm 3.0$ & 0.34 & $24.6 \pm 2.6$ & $24.4 \pm 2.9$ & 0.71 \\
\hline Waist circumference $(\mathrm{cm})$ & $89.6 \pm 7.4$ & $90.3 \pm 8.3$ & 0.69 & $89.4 \pm 7.8$ & $90.4 \pm 8.4$ & 0.45 & $90.9 \pm 6.3$ & $90.1 \pm 8.4$ & 0.64 \\
\hline \multicolumn{10}{|l|}{ Laboratory variables } \\
\hline Glucose $(\mathrm{mmol} / \mathrm{L})$ & $5.9 \pm 1.0$ & $5.9 \pm 1.4$ & 0.98 & $5.9 \pm 1.3$ & $5.8 \pm 1.4$ & 0.91 & $5.6 \pm 1.1$ & $5.9 \pm 1.4$ & 0.36 \\
\hline Total cholesterol (mmol/L) & $4.9 \pm 1.0$ & $5.1 \pm 0.9$ & 0.42 & $5.0 \pm 1.1$ & $5.1 \pm 0.9$ & 0.43 & $4.9 \pm 0.9$ & $5.1 \pm 0.9$ & 0.27 \\
\hline Triglyceride (mmol/L) & $1.5 \pm 1.3$ & $1.3 \pm 0.8$ & 0.30 & $1.4 \pm 0.7$ & $1.3 \pm 0.9$ & 0.44 & $1.3 \pm 0.7$ & $1.4 \pm 0.8$ & 0.82 \\
\hline HDL cholesterol (mmol/L) & $1.3 \pm 0.3$ & $1.4 \pm 0.4$ & 0.73 & $1.3 \pm 0.3$ & $1.4 \pm 0.4$ & 0.04 & $1.4 \pm 0.4$ & $1.4 \pm 0.4$ & 0.41 \\
\hline LDL cholesterol (mmol/L) & $3.3 \pm 0.8$ & $3.4 \pm 0.9$ & 0.35 & $3.4 \pm 1.1$ & $3.4 \pm 0.8$ & 0.74 & $3.2 \pm 0.8$ & $3.5 \pm 0.8$ & 0.13 \\
\hline $\mathrm{CRP}(\mathrm{mg} / \mathrm{L})$ & $0.8 \pm 0.8$ & $1.7 \pm 3.6$ & 0.19 & $1.6 \pm 3.2$ & $1.7 \pm 3.5$ & 0.91 & $1.5 \pm 2.4$ & $1.7 \pm 3.6$ & 0.83 \\
\hline \multicolumn{10}{|l|}{ CACS $^{\dagger}$} \\
\hline Median [interquartile range] & $172[5,468]$ & $17[0,149]$ & $<0.01$ & $62[9,376]$ & $11[0,136]$ & $<0.01$ & $133[4,789]$ & $17[0,148]$ & $<0.01$ \\
\hline
\end{tabular}

Values are presented as means \pm standard deviations or as numbers (\%).

Abbreviations see in Tables 1,2 .

*Information regarding exposure to smoking was missing in 27 subjects.

$\mathrm{P}$ values were calculated using Mann-Whitney $\mathrm{U}$ test $^{\dagger}$ or Fisher's exact test ${ }^{\ddagger}$ for categorical variables, and t-test for continuous variables.

tion between CAC scores and cerebral SVDs were evaluated using the nonparametric Mann-Whitney $U$ test due to the skewed distribution of CAC scores. Binomial logistic regression analyses were used to study relations between cerebral SVDs and CAC by treating each cerebral SVD as a dependent variable. The initial models consisted of adjusting variables, which included gender, age, hypertension, diabetes, hypercholesterolemia and exposure to smoking. The extended models further included systolic BP, glucose, TC and CRP. Statistical analyses were performed using SAS version 9.1 (SAS Institute Inc, Cary, NC, USA) and SPSS 17 (SPSS Inc, Chicago, IL, USA). Two-tailed P values of $<0.05$ were considered significant and values are presented as frequencies (percentages), means \pm standard deviations, or as medians [interquartile ranges], as appropriate.

\section{Results}

We first compared the distribution of baseline variables and risk factor profiles between the original $\geq 65$-year-old cohort $(n=672)$ and the enrolled subjects with brain MRI $(n=312)$. Overall, the distribution of baseline demographic variables and risk factor profiles are not significantly deviated (Table 1).

In the 312 subjects with a brain MRI, the prevalence of CAC (CAC score of $>0$ ) was $71.3 \%$ for males and $50.0 \%$ for females. The distributions of baseline characteristics in relation to CAC severity are presented in Table 2 . The prevalence of advanced WML, SLI and CMB increased significantly as CAC severity increased ( $\mathrm{P}$ for trends; $\mathrm{P}<0.01$, $\mathrm{P}<0.01$ and $\mathrm{P}=0.01$, respectively). Clinical and laboratory profiles according to each cerebral SVD are described in Table 3. Subjects with advanced WML, SLI, or CMB had higher CAC scores $(\mathrm{P}<0.01)$. As shown in Table 4 , subjects with moderate-to-severe CAC (CAC score of $\geq 100$ ) were found to have an increased odds of having advanced WML (adjusted odds ratio and 95\% confidence interval; 4.69 and 1.30-16.98; $\mathrm{P}=0.02)$, SLI (5.04 and 1.86-13.63; $\mathrm{P}<0.01)$ and $\mathrm{CMB}$ (6.07 and 1.54-23.94; $\mathrm{P}=0.01)$ after adjusting for relevant clinical and laboratory factors, in both initial and extended model of multivariate analysis.

\section{Discussion}

In this study, we have documented a robust association between moderate-to-extensive CAC (CAC score of $\geq 100$ ) and increased odds of having cerebral SVDs, including WML, SLI and CMB. Furthermore, these relations remained true after adjusting for gender, age, hypertension, diabetes, hypercholesterolemia and exposure to smoking, as well as systolic BP, glucose, TC and CRP.

The virtue of CAC scoring lies in its ability to predict coronary heart disease in healthy individuals with intermediate cardiovascular risks, not in the quantification of the amount of calcium in coronary arteries per se. Similarly, cerebral SVD are closely related to the development of future stroke, cognitive impairment, or antithrombotic-related fatal complications in the brain. WML is associated with information processing speed and executive function deficits, ${ }^{23-25}$ gait disturbance in the elderly, ${ }^{26}$ the risk of ischemic and hemorrhagic stroke, ${ }^{27-29}$ and anticoagulation-related cerebral 


\begin{tabular}{|c|c|c|c|}
\hline \multirow[b]{3}{*}{ Initial model } & \multicolumn{3}{|c|}{ Adjusted OR (95\%Cl) } \\
\hline & $\begin{array}{l}\text { Advanced white } \\
\text { matter lesion }\end{array}$ & $\begin{array}{c}\text { Silent lacunar } \\
\text { infarction }\end{array}$ & $\begin{array}{c}\text { Cerebral } \\
\text { microbleeds }\end{array}$ \\
\hline & & & \\
\hline No CAC (CACS, 0) & 1.00 (referent) & 1.00 (referent) & 1.00 (referent) \\
\hline Mild CAC (CACS, 1-99) & $1.84(0.51-6.63)$ & $2.39(0.95-6.01)$ & $3.02(0.78-11.78)$ \\
\hline Moderate-to-extensive CAC (CACS, $\geq 100$ ) & $4.69(1.30-16.98)^{\star}$ & $4.59(1.76-11.92)^{\dagger}$ & $5.67(1.47-21.86)^{*}$ \\
\hline \multicolumn{4}{|l|}{ Extended model } \\
\hline No CAC (CACS, 0) & 1.00 (referent) & 1.00 (referent) & 1.00 (referent) \\
\hline Mild CAC (CACS, 1-99) & $1.96(0.53-7.23)$ & $2.37(0.92-6.13)$ & $3.01(0.76-11.87)$ \\
\hline Moderate-to-extensive CAC (CACS, $\geq 100$ ) & $4.99(1.33-18.73)^{\star}$ & $5.04(1.86-13.63)^{\dagger}$ & $6.07(1.54-23.94)^{\star}$ \\
\hline
\end{tabular}

OR, odds ratio; $\mathrm{Cl}$, confidence interval. Other abbreviations see in Tables 1,2 .

Initial model was adjusted for age, gender, hypertension, diabetes, hypercholesterolemia and exposure to smoking.

The extended model was additionally adjusted for systolic blood pressure, glucose, total cholesterol and CRP.

${ }^{*} \mathrm{P}<0.05, \mathrm{t} \mathrm{P}<0.01$ for comparison with no $\mathrm{CAC}$.

hemorrhage. ${ }^{30}$ SLI is an arterial occlusive lesion per se, and the presence of SLI in asymptomatic individuals implies increased risks of subsequent stroke, ${ }^{31,32}$ mild cognitive impairment and apparent dementia including Alzheimer's disease. ${ }^{33,34} \mathrm{CMB}$, a minute bleeding focus with surrounding tissue damage, has been also suggested to predict the future risk of symptomatic cerebral hemorrhage after stroke, ${ }^{35,36}$ and to contribute to clinical deficit and executive dysfunction. ${ }^{37}$

CAC is considered a part of subclinical atherosclerosis and the development of CAC is also related to cardiovascular risk factors. ${ }^{1,38}$ Recent progress has further elucidated associations between CAC and the development of atherosclerosis in other vascular beds, such as hypertensive retinopathy, carotid intima-media thickness, peripheral artery disease and early stage nephropathy. ${ }^{10-13}$ The development of cerebral SVDs is also closely related to cardiovascular risk factors including hypertension and reflects arteriolosclerosis in smaller cerebral vasculatures. ${ }^{15,39}$ Furthermore, endothelial dysfunction may also provide an explanatory bridge between cerebral SVDs and CAC. The initial developments of atherosclerotic plaque and $\mathrm{CAC}$ are also related to the endothelial dysfunction and to the presence of stimuli noxious to vascular walls. ${ }^{40,41}$ Endothelial dysfunction has been proposed to interact with the development of cerebral WML via the extravasation of toxic plasma constituents into cerebral parenchyma, which induce localized inflammation, arteriolar thickening and eventually sublethal ischemia. ${ }^{42}$ SLI is related to lipohyalinosis and fibrinoid necrosis of cerebral arteriolar walls ${ }^{43}$ and $\mathrm{CMB}$ involves the extravasation of blood at the microscopic level through fragile vascular walls. ${ }^{44}$ In spite of different radiological phenotypes in each cerebral SVDs, risk factors and genetic factors trigger accumulation of vascular wall pathology and loss of smooth muscle cells with luminal narrowing, and ultimately lead to blood brain barrier damage and microscopic vascular rupture, thus causing cerebral SVDs..$^{45}$

The association between cerebral SVDs and CAC supports the notion that a shared pathophysiologic process, such as systemic atherosclerosis, may contribute to coronary artery diseases and microvascular diseases in cerebral arterioles. At present, we cannot conclude an exact common mechanism for CAC and cerebral SVDs, or mechanisms underlying asymptomatic disease processes that involve arteries of different sizes. However, in view of the high incidence of coexisting coronary heart disease and stroke, a common mechanism involving both CAC and cerebral SVDs has been

\section{suggested. ${ }^{46}$}

Our study should be interpreted with caution because of its retrospective nature, the limited size of our study population and because of its cross-sectional design. In spite of the well-known rarity of SVD in the younger population, excluding the $<65$-year-old population to maximize statistical comparability in our analyses may have introduced bias. Furthermore, the healthy volunteer effect may have introduced bias and limits generalizations based on our results. ${ }^{47}$ In addition, we failed to collect information on the medication history and cognitive status of the included individuals.

From our study, the association between cerebral SVDs and $\mathrm{CAC}$ was detected after adjusting for cardiovascular risk factors and other relevant laboratory parameters. We are not here to argue that either CAC or SVDs cause each other, or that CAC may predict future risk of stroke or dementia. Only sufficiently powered prospective studies could prove such a hypothesis. Rather, we were able to document the shared pathogenesis of both subclinical phenomena and thereby pulling cerebral SVDs into the risk pools of systemic cardiovascular diseases and high CAC scores.

\section{Acknowledgments}

This study was supported by grants from the Korean Health 21 R\&D Project, Ministry of Health and Welfare, Republic of Korea (A060171, A080503 and A090529). The funding organization had no role in the design, conduct, or analysis of this study, or in the preparation of this report.

\section{Disclosure}

Conflict of Interest: The authors have no potential conflict of interest to report concerning this article.

\section{References}

1. Greenland P, Bonow RO, Brundage BH, Budoff MJ, Eisenberg MJ, Grundy SM, et al. ACCF/AHA 2007 clinical expert consensus document on coronary artery calcium scoring by computed tomography in global cardiovascular risk assessment and in evaluation of patients with chest pain. Circulation 2007; 115: 402-426.

2. Arad Y, Goodman KJ, Roth M, Newstein D, Guerci AD. Coronary calcification, coronary disease risk factors, C-reactive protein, and atherosclerotic cardiovascular disease events: The St. Francis heart study. J Am Coll Cardiol 2005; 46: 158 - 165.

3. Taylor AJ, Bindeman J, Feuerstein I, Cao F, Brazaitis M, O'Malley PG. Coronary calcium independently predicts incident premature coronary heart disease over measured cardiovascular risk factors: Mean three-year outcomes in the prospective army coronary calcium (PACC) project. J Am Coll Cardiol 2005; 46: 807-814.

4. Folsom AR, Kronmal RA, Detrano RC, O'Leary DH, Bild DE, 
Bluemke DA, et al. Coronary artery calcification compared with carotid intima-media thickness in the prediction of cardiovascular disease incidence: The multi-ethnic study of atherosclerosis (MESA). Arch Intern Med 2008; 168: 1333-1339.

5. Kim BJ, Choi SY, Lee SH, Kim CK, Ryu WS, Han MK, et al. Advanced coronary artery calcification is associated with ischemic stroke. Cerebrovasc Dis 2010; 30: 93-100.

6. Raggi P, Cooil B, Shaw LJ, Aboulhson J, Takasu J, Budoff M, et al. Progression of coronary calcium on serial electron beam tomographic scanning is greater in patients with future myocardial infarction. Am J Cardiol 2003; 92: 827-829.

7. Raggi $\mathrm{P}$, Callister TQ, Shaw LJ. Progression of coronary artery calcium and risk of first myocardial infarction in patients receiving cholesterol-lowering therapy. Arterioscler Thromb Vasc Biol 2004; 24: $1272-1277$.

8. Detrano R, Guerci AD, Carr JJ, Bild DE, Burke G, Folsom AR, et al. Coronary calcium as a predictor of coronary events in four racial or ethnic groups. $N$ Engl J Med 2008; 358: 1336-1345.

9. Greenland P, LaBree L, Azen SP, Doherty TM, Detrano RC. Coronary artery calcium score combined with Framingham score for risk prediction in asymptomatic individuals. JAMA 2004; 291: 210215.

10. Wong TY, Cheung N, Islam FMA, Klein R, Criqui MH, Cotch $\mathrm{MF}$, et al. Relation of retinopathy to coronary artery calcification: The multi-ethnic study of atherosclerosis. Am J Epidemiol 2008; 167: $51-58$.

11. Davis PH, Dawson JD, Mahoney LT, Lauer RM. Increased carotid intimal-medial thickness and coronary calcification are related in young and middle-aged adults: The Muscatine study. Circulation 1999; 100: 838-842.

12. Ix JH, Katz R, Kestenbaum B, Fried LF, Kramer H, StehmanBreen $\mathrm{C}$, et al. Association of mild to moderate kidney dysfunction and coronary calcification. J Am Soc Nephrol 2008; 19: 579-585.

13. Tsuchiya M, Suzuki E, Egawa K, Nishio Y, Maegawa H, Inoue S, et al. Stiffness and impaired blood flow in lower-leg arteries are associated with severity of coronary artery calcification among asymptomatic type 2 diabetic patients. Diabetes Care 2004; 27: $2409-2415$.

14. Mitsutake R, Miura S, Kawamura A, Saku K. Are metabolic factors associated with coronary artery stenosis on MDCT? Circ J 2009; 73: $132-138$

15. Gallego J, Martinez-Vila E. Asymptomatic cerebrovascular disease and systemic diagnosis in stroke, atherothrombosis as a disease of the vascular tree. Cerebrovasc Dis 2005; 20: $1-10$.

16. Carr JJ, Danitschek JA, Goff DC, Crouse JR 3rd, D'Agostino R, Chen MY, et al. Coronary artery calcium quantification with retrospectively gated helical CT: Protocols and techniques. Int J Cardiovasc Imaging 2001; 17: 213-220.

17. Agatston AS, Janowitz WR, Hildner FJ, Zusmer NR, Viamonte M $\mathrm{Jr}$, Detrano R. Quantification of coronary artery calcium using ultrafast computed tomography. J Am Coll Cardiol 1990; 15: 827 832.

18. Fazekas F, Chawluk JB, Alavi A, Hurtig HI, Zimmerman RA. MR signal abnormalities at $1.5 \mathrm{~T}$ in Alzheimer's dementia and normal aging. Am J Roentgenol 1987; 149: 351-356.

19. Vermeer SE, Longstreth WT Jr, Koudstaal PJ. Silent brain infarcts: A systematic review. Lancet Neurol 2007; 6: 611-619.

20. Lee SH, Bae HJ, Yoon BW, Kim H, Kim DE, Roh JK. Low concentration of serum total cholesterol is associated with multifocal signal loss lesions on gradient-echo magnetic resonance imaging: Analysis of risk factors for multifocal signal loss lesions. Stroke 2002; 33: 2845-2849.

21. Friedewald WT, Levy RI, Fredrickson DS. Estimation of the concentration of low-density lipoprotein cholesterol in plasma, without use of the preparative ultracentrifuge. Clin Chem 1972; 18: 499-502.

22. Rumberger JA, Brundage BH, Rader DJ, Kondos G. Electron beam computed tomographic coronary calcium scanning: A review and guidelines for use in asymptomatic persons. Mayo Clin Proc 1999; 74: $243-252$.

23. Prins ND, van Dijk EJ, den Heijer T, Vermeer SE, Jolles J, Koudstaal PJ, et al. Cerebral small-vessel disease and decline in information processing speed, executive function and memory. Brain 2005; 128: $2034-2041$.

24. O'Sullivan M, Morris RG, Huckstep B, Jones DK, Williams SCR, Markus HS. Diffusion tensor mri correlates with executive dysfunction in patients with ischaemic leukoaraiosis. J Neurol Neurosurg Psychiatry 2004; 75: 441-447.
25. Sonohara K, Kozaki K, Akishita M, Nagai K, Hasegawa H, Kuzuya $\mathrm{M}$, et al. White matter lesions as a feature of cognitive impairment, low vitality and other symptoms of geriatric syndrome in the elderly. Geriatr Gerontol Int 2008; 8: 93-100.

26. Briley DP, Wasay M, Sergent S, Thomas S. Cerebral white matter changes (leukoaraiosis), stroke, and gait disturbance. J Am Geriatr Soc 1997; 45: 1434-1438.

27. Inzitari D, Cadelo M, Marranci ML, Pracucci G, Pantoni L. Vascular deaths in elderly neurological patients with leukoaraiosis. $J$ Neurol Neurosurg Psychiatry 1997; 62: 177-181.

28. Streifler JY, Eliasziw M, Benavente OR, Alamowitch S, Fox AJ, Hachinski VC, et al. Prognostic importance of leukoaraiosis in patients with symptomatic internal carotid artery stenosis. Stroke 2002; 33: $1651-1655$.

29. Lee SH, Kim BJ, Ryu WS, Kim CK, Kim N, Park BJ, et al. White matter lesions and poor outcome after intracerebral hemorrhage: A nationwide cohort study. Neurology 2010; 74: 1502-1510.

30. Gorter JW. Major bleeding during anticoagulation after cerebral ischemia: Patterns and risk factors: Stroke prevention in reversible ischemia trial (SPIRIT): European atrial fibrillation trial (EAFT) study groups. Neurology 1999; 53: 1319-1327.

31. Bernick C, Kuller L, Dulberg C, Longstreth Jr WT, Manolio T, Beauchamp N, et al. Silent MRI infarcts and the risk of future stroke: The cardiovascular health study. Neurology 2001; 57: $1222-$ 1229.

32. Vermeer SE, Hollander M, van Dijk EJ, Hofman A, Koudstaal PJ, Breteler MMB. Silent brain infarcts and white matter lesions increase stroke risk in the general population: The Rotterdam scan study. Stroke 2003; 34: 1126-1129.

33. Lopez OL, Jagust WJ, Dulberg C, Becker JT, DeKosky ST, Fitzpatrick A, et al. Risk factors for mild cognitive impairment in the cardiovascular health study cognition study: Part 2. Arch Neurol 2003; 60: 1394-1399.

34. Vermeer SE, Prins ND, den Heijer T, Hofman A, Koudstaal PJ, Breteler MMB. Silent brain infarcts and the risk of dementia and cognitive decline. $N$ Engl J Med 2003; 348: 1215-1222.

35. Greenberg SM, Eng JA, Ning M, Smith EE, Rosand J. Hemorrhage burden predicts recurrent intracerebral hemorrhage after lobar hemorrhage. Stroke 2004; 35: 1415-1420.

36. Soo YO, Yang SR, Lam WW, Wong A, Fan YH, Leung HH, et al. Risk vs benefit of anti-thrombotic therapy in ischaemic stroke patients with cerebral microbleeds. J Neurol 2008; 255: 16791686.

37. Werring DJ, Frazer DW, Coward LJ, Losseff NA, Watt H, Cipolotti $\mathrm{L}$, et al. Cognitive dysfunction in patients with cerebral microbleeds on T2*-weighted gradient-echo MRI. Brain 2004; 127: 22652275 .

38. Kimura T, Itoh T, Fusazaki T, Matsui H, Sugawara S, Ogino Y, et al. Low-density lipoprotein-cholesterol/high-density lipoproteincholesterol ratio predicts lipid-rich coronary plaque in patients with coronary artery disease: Integrated-backscatter intravascular ultrasound study. Circ J 2010; 74: 1392-1398.

39. Kim JE, Shin JS, Jeong JH, Choi KG, Park KD, Kim S. Relationships between 24-hour blood pressures, subcortical ischemic lesions, and cognitive impairment. J Clin Neurol 2009; 5: 139-145.

40. Berliner JA, Navab M, Fogelman AM, Frank JS, Demer LL, Edwards PA, et al. Atherosclerosis: Basic mechanisms: Oxidation, inflammation, and genetics. Circulation 1995; 91: 2488-2496.

41. Bellasi A, Raggi P. Diagnostic and prognostic value of coronary artery calcium screening. Curr Opin Cardiol 2005; 20: 375-380.

42. Wardlaw JM, Sandercock PAG, Dennis MS, Starr J, Kalimo H. Is breakdown of the blood-brain barrier responsible for lacunar stroke, leukoaraiosis, and dementia? Stroke 2003; 34: 806-812.

43. Fisher CM. The arterial lesions underlying lacunes. Acta Neuropathol (Berl) 1968; 12: 1-15.

44. Tanaka A, Ueno Y, Nakayama Y, Takano K, Takebayashi S. Small chronic hemorrhages and ischemic lesions in association with spontaneous intracerebral hematomas. Stroke 1999; 30: $1637-$ 1642.

45. Pantoni L. Cerebral small vessel disease: From pathogenesis and clinical characteristics to therapeutic challenges. Lancet Neurol 2010; 9: 689-701

46. Gongora-Rivera F, Labreuche J, Jaramillo A, Steg PG, Hauw JJ, Amarenco P. Autopsy prevalence of coronary atherosclerosis in patients with fatal stroke. Stroke 2007; 38: $1203-1210$.

47. Froom P, Melamed S, Kristal-Boneh E, Benbassat J, Ribak J. Healthy volunteer effect in industrial workers. $J$ Clin Epidemiol 1999; 52: 731-735. 